\title{
O LETRAMENTO DIGITAL NA FORMAÇÃO DE PROFESSORES: uma revisão sistemática das produções
}

\author{
Késsia M. de P. Moura ${ }^{1}$, Marie Jane S. Carvalho ${ }^{1}$, Mirian Mion ${ }^{1}$ \\ ${ }^{1}$ Programa de Pós-Graduação em Informática na Educação (PGIE) - Universidade \\ Federal do Rio Grande do Sul (UFRGS) \\ \{kessiamileny@yahoo.com.br, mariejsc@gmail.com, buizmion@hotmail.com\}
}

\begin{abstract}
Technologies have brought other conjunctures and perspectives to social practices. To search for the insertion of digital technologies of information and communication in the formative contexts is to seek to problematize the perceptions, appropriations and significations of teachers and students on the question. This paper aimed to identify the Brazilian scientific productions (theses and dissertations) and international (articles) regarding digital literacy in teacher training, in a 5-year cut between 2014 and 2018. We use the systematic review as a methodological procedure, with the help of the software Parsifal, punctuating the equation of which research objectives these productions reveal. As results we validate 51 papers, which point out the configurations of the training proposals with uses of the digital technologies that seek to respond to the new social dynamics that the student-teachers need to be able to. The notes of these researches open up ways to strengthen the formative dynamics and bring essential glances to the teaching practice, as well as new objects for the searches.
\end{abstract}

Resumo. As tecnologias trouxeram outras conjunturas e perspectivas às práticas sociais. Pesquisar a inserção das tecnologias digitais da informação e comunicação nos contextos formativos é buscar problematizar as percepções, apropriações $e$ significações de professores e alunos sobre a questão. Este texto buscou identificar as produções científicas brasileiras (teses e dissertações) e internacionais (artigos) a respeito do letramento digital na formação de professores, num recorte de 5 anos, entre os anos de 2014 a 2018. Utilizamos a revisão sistemática como procedimento metodológico, com o auxílio do software Parsifal, pontuando a equação de quais objetivos de pesquisa essas produções revelam. Como resultados validamos 51 trabalhos, que apontam as configurações das propostas de formação com usos das tecnologias digitais que procuram responder às novas dinâmicas sociais que os alunosprofessores precisam estar aptos. Os apontamentos dessas pesquisas abrem caminhos para fortalecer as dinâmicas formativas e trazer olhares essenciais à prática docente, bem como novos objetos para as pesquisas.

\section{Introdução}

Um novo parâmetro social foi desenhado a partir das tecnologias digitais de informação e comunicação (TDIC), que suscitaram e suscitam outras maneiras dos sujeitos conhecerem e atuarem no mundo, em tempos e espaços diferentes. Considerando o potencial de utilização das tecnologias em novas situações de aprendizagem, a questão 
do letramento digital ganha propriedade por estar associada a outras maneiras de aprender e lidar com a leitura e a escrita, agora em formato digital. É outra percepção do aprender, em que as relações que se estabelece com o meio (recurso) apresentam-se como uma alternativa de interagir, escolher e participar muito mais capaz de desenvolver e aumentar o sentido e a imaginação, ampliando e complexificando as funções cognitivas (Lévy, 1999; Kenski, 2007).

A formação desse professor não pode estar alheia aos novos processos da dinâmica social a respeito das tecnologias, deve problematizá-las e incorporá-las as propostas formativas, possibilitando o desenho de um profissional que consiga dinamizar sua prática educativa em função das novas necessidades educativas de seus alunos. Da mesma forma, as pesquisas voltadas à educação não podem ignorar suas implicações e potencialidades na forma de pensar e estudar o processo educativo.

Dito isto, esse texto tem como objetivo identificar estudos nacionais e internacionais sobre o tema letramento digital na formação de professores, aclarando os objetivos buscados pelos pesquisadores, através de uma revisão sistemática, entre os anos de 2014 e 2018.

\title{
2. $O$ Letramento digital e as emergências no contexto educativo
}

As tecnologias marcam outro processo de construção de conhecimento. Com o uso crescente de recursos e mídias digitais, as exigências de aprendizagem ganham mais propriedade e alinham-se às necessidades dos novos modos de comunicação, por conseguinte, de letramentos e linguagens que o tempo presente traz. Haja vista isso, o letramento adquire outras complexidades e possibilidades, dadas em formatos multimodais como resposta à nova conjuntura social (BUZATO, 2006, p. 16).

As práticas de leitura e escrita, agora em tela, acarretam implicações sobre o estado ou condição dos sujeitos letrados (SOARES, 2002, p. 150), ampliando as formas de aprender a aprender, de acesso às leituras e as maneiras de escrever e socializar os textos. Nesse contexto situa-se o letramento digital, que associa o domínio e a utilização competente da leitura e da escrita perante as tecnologias da informação e comunicação, compelindo outra forma de construir, organizar e divulgar conhecimentos.

As TDIC ampliam as formas de aprender a aprender, de acesso às leituras e as maneiras de escrever e socializar os textos, porém exigem leitores e produtores de textos mais capacitados e interativos com as mídias digitais, ou seja, as tecnologias demandam outras habilidades e competências de lidar com a leitura e a escrita. Nesse viés, destaca Xavier (2005, p. 2) que o letramento digital,

\begin{abstract}
implica realizar práticas de leitura e escrita diferentes das formas tradicionais de letramento e alfabetização. Ser letrado digital pressupõe assumir mudanças nos modos de ler e escrever os códigos e sinais verbais e não-verbais, como imagens e desenhos, se compararmos às formas de leitura e escrita feitas no livro, até porque o suporte sobre o qual estão os textos digitais é a tela, também digital.
\end{abstract}

Cada novo aparato digital utilizado nos processos educativos formais desempenha papéis de mediação nessa reconfiguração e mediação da comunicação e da linguagem entre os sujeitos, contextos e meios, que interagem e transformam suas 
VIII Congresso Brasileiro de Informática na Educação (CBIE 2019)

Anais do XXX Simpósio Brasileiro de Informática na Educação (SBIE 2019)

relações e contextos. Para Vieira (2013, p. 4), "escrita e leitura dialogam, mesclam-se e se interpenetram a partir do advento das várias tecnologias. [...] um modelo de autoria centrado em editores, uma vez que as mídias digitais permitem que uma diversidade de gêneros seja produzida e difundida".

Porém, o uso das TDIC deve superar a perspectiva de domínio técnico puramente dos recursos tecnológicos. Sobretudo, deve enveredar-se por caminhos que favoreçam a reconstrução de velhas práticas educativas (COUTINHO; LISBOA, 2011; PORTO, 2006; KENSKI, 2007). Para tanto, a formação desse professor precisa estar alinhada a essas novas demandas e buscar mecanismos de usos e apropriações dos recursos digitais.

Os cursos de formação devem funcionar então como espaços de efetivação e reverberação de outras práticas de leitura e escrita, visto que formam agentes de letramento que precisam se apropriar das novas formas de ler e escrever para dar conta das demandas sociais, ou seja, precisam conhecer as linguagens e os gêneros digitais que norteiam as práticas dos alunos.

\section{Procedimentos da Revisão Sistemática}

Pensando nas escolhas de técnicas e procedimentos encontramos no mapeamento sistemático de literatura um importante limítrofe para entender como nosso objeto de estudo tem sido tratado em nível nacional e internacional. Por revisão sistemática aqui entendemos a pesquisa que utiliza "dados da literatura sobre determinado tema", como colocam Sampaio e Mancini (2007, p. 84), que tem dentre as muitas vantagens o levantamento de espectros de maior relevância para o estudo, de maneira detalhada e confiável na bibliografia encontrada. As revisões analisam "um conjunto menor de estudos, pois têm objetivos bastante específicos e focam em aprofundar os conhecimentos já existentes em um determinado tema, como a comparação entre a eficácia de diferentes métodos" (KLOCK, 2018, p. 2).

Ainda sobre este modo de pesquisar, Conforto et al. (2011) lembram a pouca atenção que este modelo tem recebido, mesmo com o potencial para explorar temas emergentes inclusive. Por isso, deixa-se de promover relevantes ligações e correlações entre estudos, negligenciando-se elementos que poderiam ser impetrados no desenvolvimento de uma teoria.

Neste texto fizemos uma revisão sistemática de caráter descritivo, sem perder de vista caminhos futuros ou agendas de pesquisa que ampliem e redimensionem o objeto de estudo. Para tanto, contamos com o auxílio do software de apoio Parfisal, com recorte temporal entre os anos de 2014 a 2018. Sobre o Parsifal, destacamos que é uma ferramenta on-line para revisão de literatura, que apresenta um protocolo de busca dos trabalhos, no qual se definem os descritores e norteadores que atendem às pretensões de quem a realiza.

Segundo Klock (2018), a revisão sistemática deve seguir o protocolo definido. Nesse sentido, no planejamento dessa revisão sistemática definimos como primeiro norteador traçado para a busca, o mapeamento das produções que discutem o letramento digital na formação de professores. Com isso, nossa string de busca foi ("formação de 
VIII Congresso Brasileiro de Informática na Educação (CBIE 2019)

Anais do XXX Simpósio Brasileiro de Informática na Educação (SBIE 2019)

professores" and "letramento digital"). A partir disso pudemos especificar a questão que esperávamos ser atendidas nos trabalhos que constariam nos bancos de dados, no qual centramos em: Que objetivos de pesquisa essas produções revelam?

Em nível nacional visitamos a Biblioteca Digital Brasileira de Teses e Dissertações (BDTD), com descritores nas ciências humanas, educação e linguística. Encontramos 243 dissertações e 89 teses, publicadas entre os anos de 2014 e 2018. Desse total, fizemos a leitura dos resumos, filtrando apenas 38 pesquisas, sendo 25 dissertações e 13 teses, que atendiam mais prontamente ao nosso interesse e critérios de busca, equivalente a 11, 45\% dos trabalhos aceitos.

Em nível internacional nas bases de dados do Scopus e Scielo, tendo como critérios de inclusão artigos disponíveis para download; escritos em espanhol, inglês ou português; publicados a partir de 2014; trabalhos primários completos acima de dez páginas. Em nossa busca inicial encontramos 30 trabalhos, para os quais realizamos um filtro com a leitura dos resumos, que resultou em 13 trabalhos aceitos, visto se adequarem aos nossos norteadores, que corresponde a 43,3\% dos trabalhos encontrados. Na Tabela 1, vemos o quantitativo de trabalhos publicados por ano.

Tabela 1 - Quantidade de trabalhos por ano de publicação

\begin{tabular}{c|c|c|c|}
\hline \multirow{2}{*}{ Ano } & Bdtd & Scielo e scopus & $\begin{array}{c}\text { Quantidade de } \\
\text { trabalhos }\end{array}$ \\
\cline { 2 - 4 } $\mathbf{2 0 1 4}$ & 5 & 2 & 7 \\
\hline $\mathbf{2 0 1 5}$ & 10 & 2 & 12 \\
\hline $\mathbf{2 0 1 6}$ & 10 & 2 & 12 \\
\hline $\mathbf{2 0 1 7}$ & 10 & 5 & 15 \\
\hline $\mathbf{2 0 1 8}$ & 3 & 2 & 5 \\
\hline Total & $\mathbf{3 8}$ & $\mathbf{1 3}$ & $\mathbf{5 1}$ \\
\hline
\end{tabular}

Fonte: Elaborado pelas autoras deste texto.

\section{Achados}

Quanto aos objetivos, os dados assentem categorias em relação a: (1) percepções, concepções, crenças e sentidos do letramento digital nos processos formativos dos professores; (2) usos e apropriações das tecnologias digitais para o desenvolvimento do letramento no âmbito da formação. Na primeira categoria é possível destacar os trabalhos de dezoito pesquisadores, que trazem expressamente essas palavras-chave ou sinônimos na apresentação de seus objetivos (Quadro 2).

Quadro 2 - Trabalhos sobre percepções, concepções, crenças e sentidos do letramento digital nos processos formativos dos professores

\begin{tabular}{|l|l|}
\hline \multicolumn{1}{|c|}{ Trabalho } & \multicolumn{1}{c|}{ Objetivo do trabalho } \\
\hline PAVANELLI, 2014 & $\begin{array}{l}\text { Analisar os sentidos verificados nos enunciados dos professores sobre o uso das } \\
\text { tecnologias, ponderando também seus apontamentos sobre a formação continuada } \\
\text { para essa finalidade. }\end{array}$ \\
\hline HINKEL, 2014 & $\begin{array}{l}\text { Reconhecer nas trajetórias de alunos e egressos do curso de Letras da } \\
\text { Universidade da Região de Joinville - UNIVILLE - como eles percebem as } \\
\text { contribuições de sua formação inicial para a prática pedagógica no que se refere } \\
\text { ao envolvimento com tecnologias digitais. }\end{array}$ \\
\hline JOHANNESEN, M. M. & Analisar a compreensão predominante da competência digital nas escolas e na \\
\hline
\end{tabular}


VIII Congresso Brasileiro de Informática na Educação (CBIE 2019)

Anais do XXX Simpósio Brasileiro de Informática na Educação (SBIE 2019)

\begin{tabular}{|c|c|}
\hline $\begin{array}{l}\text { AND ØGRIM, L. } \\
\text { AND GIÆVER, } \\
\text { T.H., } 2014\end{array}$ & formação de professors \\
\hline \begin{tabular}{l}
\multicolumn{2}{l}{ CORTINA-PÉREZ, } \\
B. \\
GALLARDO- \\
VIGIL, M.Á. \\
JIMÉNEZ- \\
JIMÉNEZ, M.Á. \\
AND TRUJILLO- \\
TORRES, \\
2014
\end{tabular} & $\begin{array}{l}\text { Verificar o grau de alfabetização digital dos professores e se os professores têm } \\
\text { outras razões para não integrar TIC em suas salas de aula, além do analfabetismo } \\
\text { digital }\end{array}$ \\
\hline FALCÃO, 2015 & $\begin{array}{l}\text { Estudar professores em formação e crianças entre } 9 \text { e } 11 \text { anos, relacionando seus } \\
\text { conhecimentos e práticas por meio do uso de TDIC, e se há uma lacuna entre } \\
\text { esses sujeitos, considerando tais conhecimentos. }\end{array}$ \\
\hline BEZERRA, 2015 & $\begin{array}{l}\text { Compreender significados atribuídos por professores da educação básica aos } \\
\text { cursos de formação continuada do NTE na escola acerca do uso das TDIC ao } \\
\text { refletirem sobre suas experiências formativas. }\end{array}$ \\
\hline DIAS, 2015 & $\begin{array}{l}\text { Compreender o olhar do aluno em relação aos multiletramentos e tecnologias } \\
\text { digitais da Informação e Comunicação. }\end{array}$ \\
\hline TURULA, A., 2015 & $\begin{array}{l}\text { Analisar no contexto de abordagens populares de formação de professores de } \\
\text { EFL, bem como vis-a-vis a necessidade de letramento digital amplamente } \\
\text { compreendido }\end{array}$ \\
\hline $\begin{array}{l}\text { RODRÍGUEZ- } \\
\text { IZQUIERDO, R.M., } \\
2015\end{array}$ & $\begin{array}{l}\text { Estudar a opinião dos professores sobre o potencial das } \\
\text { desenvolvimento da competência intercultural }\end{array}$ \\
\hline SILVA, 2016 & $\begin{array}{l}\text { Analisar a visão de um grupo de professores e pedagogos acerca do letramento } \\
\text { digital. }\end{array}$ \\
\hline MONTES, 2016 & $\begin{array}{l}\text { Analisar as percepções e crenças dos professores de uma escola estadual do } \\
\text { município de Divino sobre o uso de TDIC e desenvolver ações que minimizassem } \\
\text { a resistência desses profissionais em usá-las em contexto educacional. }\end{array}$ \\
\hline FADINI, 2016 & $\begin{array}{l}\text { Analisar crenças de professores formadores e de professores de inglês em } \\
\text { formação em um curso de licenciatura em Letras-Inglês de uma universidade } \\
\text { federal do sudeste brasileiro. }\end{array}$ \\
\hline ARAÚJO, 2016 & $\begin{array}{l}\text { Investigar a percepção de quatro alunos-professores de inglês sobre a } \\
\text { aprendizagem e a prática pedagógica com o uso das tecnologias, observando-se } \\
\text { suas percepções acerca da inclusão das tecnologias no ensino-aprendizagem de } \\
\text { inglês bem como o fomento do letramento digital desses alunos-professores a } \\
\text { partir de uma disciplina curricular acadêmica do curso de Letras-Inglês. }\end{array}$ \\
\hline $\begin{array}{l}\text { PÉREZ-ESCODA, } \\
\text { A. AND IGLESIAS- } \\
\text { RODRÍGUEZ, A. } \\
\text { AND SÁNCHEZ- } \\
\text { GÓMEZ, M.C., } \\
2016\end{array}$ & $\begin{array}{l}\text { Avaliar os níveis de competência digital com base em um estudo anterior sobre a } \\
\text { avaliação internacional específica de alfabetização digital e habilidades digitais }\end{array}$ \\
\hline $\begin{array}{l}\text { GONÇALVES, } \\
2017\end{array}$ & $\begin{array}{l}\text { Compreender os sentidos, na voz dos acadêmicos de pedagogia para as leituras e } \\
\text { produções escritas em práticas de letramento acadêmico. }\end{array}$ \\
\hline ARAÚJO, 2017 & $\begin{array}{l}\text { Investigar a percepção de quatro alunos-professores de inglês sobre a } \\
\text { aprendizagem e a prática pedagógica com o uso das tecnologias, observando-se } \\
\text { suas percepções acerca da inclusão das tecnologias no ensino-aprendizagem de } \\
\text { inglês bem como o fomento do letramento digital desses alunos-professores a } \\
\text { partir de uma disciplina curricular acadêmica do curso de Letras-Inglês. }\end{array}$ \\
\hline $\begin{array}{l}\text { CORONA, A.G.-F. } \\
\text { AND MARTÍNEZ- } \\
\text { ABAD, F. AND } \\
\text { RODRÍGUEZ- }\end{array}$ & $\begin{array}{l}\text { Detectar o nível de competência digital de professores em formação, } \\
\text { especificamente } 316 \text { alunos da Faculdade de Educação da Universidade de } \\
\text { Salamanca }\end{array}$ \\
\hline
\end{tabular}


VIII Congresso Brasileiro de Informática na Educação (CBIE 2019)

Anais do XXX Simpósio Brasileiro de Informática na Educação (SBIE 2019)

\begin{tabular}{|l|l|}
\hline CONDE, M.-J, 2017 & \\
\hline GUTIÉRREZ- & $\begin{array}{l}\text { Descrever a construção e as características psicométricas do questionário para o } \\
\text { CASTILLO, J.-J. }\end{array}$ \\
AND Cestudo da competência digital de estudantes no ensino superior (CDAES) como \\
ALMENARA, J. & instrumento ad hoc para coletar e avaliar o grau de autopercepção da competência \\
AND ESTRADA- & digital que evidencia a formação de universitários (graus de educação infantil e \\
primária, das diversas faculdades e escolas da comunidade autônoma de & \\
\hline LADAL, L.I., 2017 & Andaluzia) \\
\hline AND LOPES, M.R. & Compreender como os professores do ensino básico do município de Viseu \\
2018 & (Portugal) realizaram a sua formação em tecnologias da informação \\
\hline
\end{tabular}

Fonte: Elaboração própria sobre os trabalhos analisados (grifos nossos).

Dentre outras agendas nesse contexto complexo e multireferenciado, Zeichner (2005) considera importante buscar formas de avaliar melhor o saber docente, sem dissociar do contexto e das práticas, que são genuinamente os espaços de sua produção. Diríamos que não há como apreender e qualificar as ações dos sujeitos sem verificar a orientação e os fundamentos que estes exprimem em suas concepções e nos significados que atribuem a algo, visto serem partes constitutivas destes, logo, elementos da identidade e profissionalização dos professores.

A nosso ver, há preocupação nos trabalhos destacados com essa pormenorização, situando uma realidade emergente em contextos educativos com inserção das tecnologias digitais para o letramento. A preocupação em situar os letramentos concebidos pelos sujeitos desvenda as compreensões em que são construídos e os significados atribuídos, ou ainda, segundo Gee (2009), constitui uma posição perante o fenômeno social.

O segundo enquadramento dos objetivos traz uma perspectiva da prática dos sujeitos, conforme categorizamos acima de usos e apropriações das tecnologias digitais para o desenvolvimento do letramento no âmbito da formação. Aqui, destacamos 33 trabalhos (Quadro 3).

Quadro 3 - Trabalhos sobre usos e apropriações das tecnologias digitais para o desenvolvimento do letramento no âmbito da formação

\begin{tabular}{|l|l|}
\hline \multicolumn{1}{|c|}{ TRABALHO } & \multicolumn{1}{c|}{ Objetivo do trabalho } \\
\hline MIGUEL, 2014 & $\begin{array}{l}\text { Verificar quais são as práticas, modos de uso, consumo, apropriação e produção } \\
\text { dos recursos digitais pelos docentes e como a formação e o acompanhamento } \\
\text { pedagógico podem influenciar/ampliar a apropriação qualificada das mídias em } \\
\text { suas práticas pedagógicas. }\end{array}$ \\
\hline JUNIOR, 2014 & $\begin{array}{l}\text { Investigar a influência da formação continuada para o letramento digital na prática } \\
\text { pedagógica dos professores dos anos iniciais do ensino fundamental da Rede } \\
\text { Municipal de Educação de Manaus-AM. }\end{array}$ \\
\hline CUSTÓDIO, 2014 & $\begin{array}{l}\text { Analisar o desenvolvimento do letramento informacional digital de professores } \\
\text { em formação inicial do curso de letras de uma instituição de ensino superior, } \\
\text { observando o processo busca por ferramentas online para o planejamento do } \\
\text { ensino de línguas. }\end{array}$ \\
\hline FERREIRA, 2015 & $\begin{array}{l}\text { Analisar e caracterizar os fóruns de discussão no ambiente Moodle do } \\
\text { PNAIC/UFSCar no ano de 2014, levando em consideração a forma de interação } \\
\text { propiciada pelo gênero em questão, focando também o letramento digital dos } \\
\text { Orientadores de Estudo. }\end{array}$ \\
\hline REZENDE, 2015 & $\begin{array}{l}\text { Investigar como se dá a formação de professores de língua portuguesa na UEL, } \\
\text { para a implementação das novas práticas letradas com forte apelo tecnológico. }\end{array}$ \\
\hline PINTO, 2015 & Sistematizar e discutir o estado da arte de pesquisas sobre letramentos digitais no \\
\hline
\end{tabular}


VIII Congresso Brasileiro de Informática na Educação (CBIE 2019)

Anais do XXX Simpósio Brasileiro de Informática na Educação (SBIE 2019)

\begin{tabular}{|c|c|}
\hline & que se referem as práticas pedagógicas de professores de lingas em formação. \\
\hline COSTA, 2015 & $\begin{array}{l}\text { Investigar sobre um curso de formação docente para professores de Ensino } \\
\text { Fundamental da escola pública, levando-se em conta conceitos sobre treinamento } \\
\text { e formação continuada. }\end{array}$ \\
\hline SILVA, 2015 & $\begin{array}{l}\text { Discutir os desafios, as possibilidades e o processo de formação continuada do } \\
\text { professor para promover o ensino de Língua Portuguesa em ambientes digitais e } \\
\text { virtuais na modalidade presencial. }\end{array}$ \\
\hline SANTOS, 2015 & $\begin{array}{l}\text { Refletir sobre o conhecimento construído a respeito da formação inicial em letras } \\
\text { em relação ao letramento digital pelos professores na UEL. }\end{array}$ \\
\hline $\begin{array}{l}\text { ALEXANDRE, } \\
2015\end{array}$ & $\begin{array}{l}\text { Analisar a contribuição da integralização curricular do Curso de Pedagogia da } \\
\text { UFC na formação dos saberes tecnológicos de seus professores. }\end{array}$ \\
\hline RIBEIRO, 2016 & $\begin{array}{l}\text { Desenvolver um curso de Letramento Informacional e Midiático (LIM) para } \\
\text { formação continuada de professores atuantes na Educação Básica, que foi } \\
\text { construído alicerçado nas abordagens de Design Thinking para Educadores e no } \\
\text { Experience Learning. }\end{array}$ \\
\hline ARROYO, 2016 & $\begin{array}{l}\text { Investigar o estatuto do link (popularmente conhecido como "ligação eletrônica" } \\
\text { em hipertextos da internet) como ponto de heterogeneidade de práticas letradas } \\
\text { acadêmicas em contexto digital. }\end{array}$ \\
\hline RAMOS, 2016 & $\begin{array}{l}\text { Investigar as contribuições de um curso de formação contínua para elaboração de } \\
\text { material educacional digital (MED), intitulado Elaboração de Material } \\
\text { Educacional Digital - Nível Básico, para o letramento digital de professores de } \\
\text { inglês. }\end{array}$ \\
\hline SANTOS, 2016 & $\begin{array}{l}\text { Analisar o processo de desenvolvimento profissional dos docentes para a } \\
\text { utilização das tecnologias de informação e comunicação (TIC) através da análise } \\
\text { e descrição da proposta do curso, das dimensões de desenvolvimento profissional } \\
\text { e da verificação das contribuições concretas do curso para os docentes. }\end{array}$ \\
\hline SOUZA, 2016 & $\begin{array}{l}\text { Analisar o processo de formação de estudantes online (idealização, práticas e } \\
\text { discursos) ao uso das mídias digitais (MD), identificando a relação entre as } \\
\text { competências a desenvolver nos estudantes e as dimensões, conhecimentos e } \\
\text { habilidades mobilizadas durante a formação que se configuram em Letramentos } \\
\text { Digitais (LD), destacando as contribuições para propostas de formação ao } \\
\text { contexto brasileiro. }\end{array}$ \\
\hline BARRETO, 2016 & $\begin{array}{l}\text { Analisar a formação do professor de inglês orientado à integração das mídias no } \\
\text { contexto do estágio supervisionado. }\end{array}$ \\
\hline $\begin{array}{lll}\text { PARK, } & \text { S. } & \text { AND } \\
\text { PARK, } & \text { K. } & \text { AND } \\
\text { YUN, } & \text { H, } & 2016\end{array}$ & $\begin{array}{l}\text { Explorar os problemas dos livros digitais que são atualmente aplicados para } \\
\text { modelar escolas e descobrir a mudança de perspectivas de professores juniores } \\
\text { sobre o livro didático para o campo escolar }\end{array}$ \\
\hline VIDAL, 2017 & $\begin{array}{l}\text { Investigar o uso das simulações virtuais como alternativa metodológica ao ensino } \\
\text { de Ciências. }\end{array}$ \\
\hline SAITO, 2017 & $\begin{array}{l}\text { Investigar os processos de co-construções webcurriculares em um curso de língua } \\
\text { inglesa, e cujas construções das aulas são mediatizadas pelas tecnologias da } \\
\text { informação e comunicação, suas ferramentas e seus recursos. }\end{array}$ \\
\hline NOGUEIRA, 2017 & $\begin{array}{l}\text { Analisar de que maneira os professores de língua inglesa do ensino médio da rede } \\
\text { pública estadual de São Paulo estão conseguindo utilizar nas aulas os } \\
\text { conhecimentos construídos nos cursos oferecidos pela Secretaria Estadual de } \\
\text { Educação e pelos Núcleos Pedagógicos, que envolvem tecnologia educacional e a } \\
\text { "Plataforma Currículo+". }\end{array}$ \\
\hline BARBETA, 2017 & $\begin{array}{l}\text { Intervir junto a dois professores do ensino médio de uma escola pública estadual } \\
\text { da cidade Londrina-PR. }\end{array}$ \\
\hline $\begin{array}{l}\text { NASCIMENTO, } \\
2017\end{array}$ & $\begin{array}{l}\text { Investigar o quanto e de que forma o Pibid de uma Universidade do Nordeste } \\
\text { brasileiro permite o trabalho com o letramento digital na formação inicial do } \\
\text { professor de inglês. }\end{array}$ \\
\hline SOUSA, 2017 & $\begin{array}{l}\text { Analisar indícios de conhecimentos para a prática pedagógica docente } \\
\text { interdisciplinar, emergentes em um contexto colaborativo de formação continuada } \\
\text { na perspectiva do letramento. }\end{array}$ \\
\hline
\end{tabular}


VIII Congresso Brasileiro de Informática na Educação (CBIE 2019)

Anais do XXX Simpósio Brasileiro de Informática na Educação (SBIE 2019)

\begin{tabular}{|c|c|}
\hline SILVA, 2017 & $\begin{array}{l}\text { Analisar como o curso de licenciatura em letras incorpora o letramento digital, } \\
\text { com ênfase no estágio supervisionado }\end{array}$ \\
\hline SILVEIRA, 2017 & $\begin{array}{l}\text { Elaborar um tutorial para o letramento midiático e digital do professor no } \\
\text { desenvolvimento do projeto rádio escolar. }\end{array}$ \\
\hline $\begin{array}{lr}\text { POMBO, L. } & \text { AND } \\
\text { CARLOS, V. } & \text { AND } \\
\text { LOUREIRO, } & \text { M.J, } \\
2017 & \end{array}$ & $\begin{array}{l}\text { Relatar as estratégias de apoio utilizadas para avaliar as práticas dos professores } \\
\text { no final de um curso de formação de professores (TTC) e analisar o seu impacto } \\
\text { na integração de tecnologias pelos professores, utilizando uma metodologia } \\
\text { baseada no design }\end{array}$ \\
\hline $\begin{array}{lr}\text { CARL, A. } & \text { AND } \\
\text { STRYDOM, } & \text { S., } \\
2017 & \end{array}$ & $\begin{array}{l}\text { Determinar se a base teórica e as perspectivas de um portfólio se alinham com as } \\
\text { práticas e atributos atuais de treinamento dos alunos durante o estágio escolar de } \\
\text { professores de uma universidade sul-africana }\end{array}$ \\
\hline JEONG, K.-O, 2017 & $\begin{array}{l}\text { Investigar um programa de educação de professores de inglês coreano como } \\
\text { língua estrangeira (EFL) que visa a desenvolver a alfabetização digital de futuros } \\
\text { professores e ajudá-los a compreender a pedagogia inovadora de aprendizagem de } \\
\text { linguagem assistida por computador (CALL) no contexto da língua coreana }\end{array}$ \\
\hline $\begin{array}{l}\text { GONÇALVES, } \\
2018\end{array}$ & $\begin{array}{l}\text { Compreender práticas de letramentos acadêmicos com TD desenvolvidas no LIFE } \\
\text { por docentes universitários com professores em formação inicial e continuada. }\end{array}$ \\
\hline BATISTA, 2018 & $\begin{array}{l}\text { Compreender como a memória digital se apresenta na modalidade de educação a } \\
\text { que se denomina educação a distância }(\mathrm{EaD}) \text { foi o objetivo da tese, de modo que } \\
\text { se pôde analisar como ela interfere neste contexto, e a partir de então, refletir a } \\
\text { respeito da formação em uma sociedade marcada pelas tecnologias do digital. }\end{array}$ \\
\hline ASSIS, 2018 & $\begin{array}{l}\text { Analisar o processo de implementação do projeto Early Bird como flagrante das } \\
\text { disputas e polêmicas que envolvem o campo da formação de professores no } \\
\text { Brasil, mais especificamente a formação de professores de LIC. }\end{array}$ \\
\hline $\begin{array}{l}\text { LLAMAS- } \\
\text { SALGUERO, F. } \\
\text { AND MACÍAS } \\
\text { GÓMEZ, E, } 2018\end{array}$ & $\begin{array}{l}\text { Comprovar se a aplicação de competência digital no processo educativo facilita a } \\
\text { geração de conhecimento nos aluno }\end{array}$ \\
\hline
\end{tabular}

Fonte: Elaboração própria sobre os trabalhos analisados (grifos nossos).

Nesse viés, pressupomos que esses pesquisadores partem do entendimento de que o fazer docente não é meramente uma dimensão técnica, articula diversas dimensões, e que todo processo de ensino-aprendizagem passa por definições curriculares, por organização institucional e pelas experiências de cunho pessoal e profissional dos docentes e discentes, que emergem na dinâmica do fazer pedagógico com o auxílio dos recursos tecnológicos. Ou seja, essas ações expressam os direcionamentos e criações curriculares fundamentadas na cibercultura, que carregam em si condicionamentos oriundos de seus usos.

Pensamos que os usos, para além das crenças e concepções da primeira categoria descrita, apresentam um campo ainda mais fértil, que se correlaciona com a dinâmica de possibilidades que as tecnologias e o campo pedagógico carregam. É por meio dos usos que as apropriações podem ser sentidas, significadas e resignificadas, e que poderemos interrogar as contribuições delas para este ou aquele objetivo educativo, para este ou aquele processo formativo. Mas, não se trata de qualquer uso. Quando falamos de letramento digital, não nos referimos a um simples domínio técnico ou habilidade ligada à tecnologia, estamos tratando de práticas sociais específicas construídas em atividades que envolvem a relação e a comunicação entre sujeitos, ou, como coloca Buzato (2006, p. 16), "conjuntos de letramentos (práticas sociais) que se apoiam, entrelaçam, e apropriam mútua e continuamente por meio de dispositivos digitais para finalidades específicas". 
VIII Congresso Brasileiro de Informática na Educação (CBIE 2019)

Anais do XXX Simpósio Brasileiro de Informática na Educação (SBIE 2019)

\section{Finalizações}

Este texto apresentou o resultado de uma revisão sistemática que identificou as teses, dissertações e artigos publicadas entre 2014 e 2018 sobre o letramento digital na formação de professores, com o auxílio do software Parsifal.

Sobre o letramento digital, vimos que as novas tecnologias trouxeram implicações aos processos de apropriação da leitura e escrita, requerendo outras práticas nos contextos formativos, de forma que sejam desenvolvidas competências para os usos e as apropriações do novo.

Os cursos de formação inicial ou continuada têm se prestado a inserir as tecnologias digitais, mas as possibilidades de usos ainda são muitas. Essa questão foi pontuada nas pesquisas, ao mesmo tempo em que levantava elementos da realidade pesquisada, com seus avanços ou lacunas no trabalho com o letramento. Isso também sugere outros olhares e caminhos para as investigações sobre a temática, caminhos que invistam tanto na visão de professores e alunos sobre as tecnologias, quanto nas apropriações que se promovem.

A revisão sistemática favoreceu um panorama pertinente sobre o que se tem pesquisado nessa questão, permitindo dizer que ainda temos um número reduzido de trabalhos e que este revela-se um campo bem fértil, visto que, quanto mais se utiliza as TDIC nos processos educativos, mais podemos problematizar e empreender estudos científicos. Como trabalhos futuros, sugerimos a ampliação dos bancos de dados e tipos de trabalhos no planejamento da pesquisa.

\section{Referencias}

BIBLIOTECA DIGITAL BRASILEIRA DE TESES E DISSERTAÇÕES. Disponível em: 〈http://bdtd.ibict.br/vufind/>. Acesso em: 10 jan. 2017.

BUZATO, M. E. K. Letramentos Digitais e Formação de Professores. In: III Congresso Ibero-Americano EducaRede, 2006, São Paulo. Anais do III Congresso IberoAmericano EducaRede. São Paulo: CENPEC, 2006, p. 81-86.

COUTINHO, C.; LISBOA, E. Sociedade da informação, do conhecimento e da aprendizagem: desafios para educação no século XXI. Revista de Educação, v. XVIII, n. 1, p. 5-22, 2011. Disponível em:

<https://repositorium.sdum.uminho.pt/bitstream/1822/14854/1/Revista_Educa\%C3\%A7 \%C3\%A3o,VolXVIII,n\%C2\%BA1_5-22.pdf>. Acesso em: 10 nov. 2016.

GEE, J. P. A situated sociocultural approach to literacy and technology. 2009.

Disponível em:

http://www.jamespaulgee.com/sites/default/files/pub/Approach\%20to\%20Literacy\%20P aper.pdf . Acesso em 2 nov. 2018.

KENSKI, V. M. Educação e tecnologias: o novo ritmo da informação. Campinas; São Paulo: Papirus, 2007. 
VIII Congresso Brasileiro de Informática na Educação (CBIE 2019)

Anais do XXX Simpósio Brasileiro de Informática na Educação (SBIE 2019)

KLOCK, A. C. T. Mapeamentos e Revisões Sistemáticos da Literatura: um Guia Teorico e Prático. Revista Cadernos de Informática, Porto Alegre, v. 10, n. 1, p. 1-9, 2018. Disponível em:

https://seer.ufrgs.br/cadernosdeinformatica/article/view/v10n1201801-09/49901.

Acesso em: 10 fev. 2018.

LÉVY, P. Cibercultura. São Paulo, SP: Ed. 34, 1999.

POSTMANN, N. Tecnopólio: a rendição da cultura à tecnologia. São Paulo: Nobel, 1994.

SAMPAIO, R. F.; MANCINI, M. C. Estudos de Revisão Sistemática: Um Guia para Síntese Criteriosa da Evidência Científica. ver.Bras.Fisioter, São Carlos, v. 11, n. 1, p. 83-89, 2007. Disponível em:

http://www.scielo.br/scielo.php?script=sci_arttext\&pid=S1413-35552007000100013.

Acesso em: 25 set. 2018.

SOARES, M. Letramento e alfabetização: as muitas facetas. Rev. Bras. Educ. [online], n. 25, pp. 5-17, 2004. Disponível em: http://www.scielo.br/pdf/rbedu/n25/n25a01.pdf. Acesso em 13 set. 2018.

VIEIRA, M. S. P. Letramento digital: o uso de tecnologias da informação e comunicação no ensino da leitura. In: Anais do SILEL. v. 3, n. 1. Uberlândia: EDUFU, 2013. Disponível em: <http://www.ileel.ufu.br/anaisdosilel/wpcontent/uploads/2014/04/silel2013_3123.pdf>. Acesso em: 13 jan. 2017.

XAVIER, A. C. S. Letramento Digital e Ensino. In: SANTOS, C. F.; MENDONÇA, M. (Org.). Alfabetização e Letramento: conceitos e relações. Belo Horizonte: Autêntica, 2005, v. 1. p. 133-148.

ZEICHNER, K. A research agenda for teacher education. In: COCHRAN-SMITH, M.; ZEICHNER, K. (Ed.). Studying teacher education: the report of the AERA panel on research and teacher education. London: Lawrence Erlbaum, 2005. p. 737-759.

Disponível em:

https://www.researchgate.net/profile/Kenneth_Zeichner/publication/303382056_A_Res earch_Agenda_for_Teacher_Education/links/573f417f08ae9f741b321ba7/A-ResearchAgenda-for-Teacher-Education.pdf?origin=publication_detail. Acesso em 10 nov. 2018. 